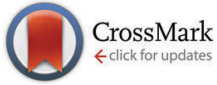

Cite this: Chem. Commun., 2015, 51,13181

Received 16th June 2015 Accepted 9th July 2015

DOI: $10.1039 / \mathrm{c5cc04972e}$

www.rsc.org/chemcomm

\section{Control of the cavity size of flexible covalent cages by silver coordination to the peripheral binding sites $\dagger$}

\author{
Lucas Kocher, Stéphanie Durot and Valérie Heitz*
}

The synthesis of covalent cages consisting of two porphyrins connected by four flexible spacers each incorporating two 1,2,3triazolyl ligands is reported. Binding of four silver(I) to the peripheral ligands induces conformational changes in solution and locks the porphyrins in a face-to-face disposition.

The design of three-dimensional (3D) architectures incorporating components that can actively participate in the guest encapsulation or reactivity performed in their cavity is a challenging task. By analogy with biological processes, ${ }^{1}$ large conformational changes in container-like systems, triggered by binding events, are expected to be efficient to control guest release and chemical reactivity. ${ }^{2}$ Such control relies on systems with components acting as regulation or guest binding sites. Modulation of the cavity size in $3 \mathrm{D}$ structures was achieved in a few systems using a chemical $^{3}$ or a photochemical signal. ${ }^{4}$ Porphyrins and their metalated forms have been incorporated in various covalent or non-covalent cage-like structures to stabilize guest molecules by coordination bonds or by various weak interactions. ${ }^{5}$ Flexible macrocycles that incorporate two metalloporphyrins and peripheral complexes have shown an allosteric control of the porphyrin reactivity based on a ligand-induced cavity size change. ${ }^{6}$ Whereas the Cu-catalysed alkyne azide coupling (CuAAC) reaction was successfully used to obtain covalent porphyrin cages of various size and rigidity, ${ }^{7}$ the triazole ligands thus formed were not yet considered as additional active sites. With the aim of building multicomponent flexible porphyrin containers with orthogonal binding sites, we have reported the synthesis of porphyrinic covalent cages with eight 3-pyridyl ligands thanks to a DABCO-templated ring-closing metathesis reaction (DABCO: 1,4-diazabicyclo[2.2.2] octane). ${ }^{8}$ Based on these results, it was envisioned to use the distal

Laboratoire de Synthèse des Assemblages Moléculaires Multifonctionnels, Institut de Chimie de Strasbourg, CNRS/UMR 7177, Université de Strasbourg, 4, rue Blaise Pascal,67000 Strasbourg, France.E-mail:v.heitz@unistra.fr

$\dagger$ Electronic supplementary information (ESI) available: Details of the synthesis and spectroscopic data of 4, 5, 6, 1, 1.DABCO, 2, $\left[\mathrm{Ag}_{4}(\mathbf{1})\right]\left(\mathrm{SbF}_{6}\right)_{4},\left[\mathrm{Ag}_{4}(2)\right](\mathrm{OTf})_{4}(\mathrm{NMR}, \mathrm{ES}-\mathrm{MS}$, UV-vis) and crystallographic data of cage 1. CCDC 1403732. For ESI and crystallographic data in CIF or other electronic format see DOI: 10.1039/c5cc04972e coordination sites incorporated in flexible porphyrin containers to adjust their cavity size.

In the present report, we describe the synthesis of a covalent and flexible zinc(II) porphyrinic cage 1 and its metal-free analogue 2 that incorporate eight 1,2,3-triazolyl ligands as peripheral coordination sites, based on a DABCO-templated CuAAC reaction. The reversible binding of the ditopic DABCO ligand on the $\mathrm{Zn}$ (II) porphyrins of cage 1 or of four $\mathrm{Ag}_{(\mathrm{I})}$ ions on the peripheral triazoles of cages $\mathbf{1}$ and $\mathbf{2}$ is demonstrated. Silver(I) is shown to act as a chemical stimulus able to fix the porphyrin cavity size of the flexible covalent cages $\mathbf{1}$ and 2 .

The porphyrin cages $\mathbf{1}$ and $\mathbf{2}$ and their corresponding silver(I)-complexed cages $\left[\mathbf{A g}_{\mathbf{4}}(\mathbf{1})\right]^{\mathbf{4 +}}$ and $\left[\mathbf{A g}_{\mathbf{4}}(\mathbf{2})\right]^{\mathbf{4 +}}$ discussed in the present study are represented in Fig. 1.

The synthesis of 1.DABCO from readily obtained precursors 3 and 6 is described in Fig. 2. The preparation of the azidefunctionalized free-base porphyrin and its zinc(II) complex 3 were already reported. ${ }^{7 c, 9}$ The TIPS-monoprotected alkyne chain 4 was obtained in 33\% yield from a statistical reaction performed on the dialkyne-functionalized diethyleneglycol ${ }^{10}$ in presence of 1 equiv. of TIPSCl. A CuAAC reaction performed on porphyrin 3 with alkyne 4 allowed to construct four out of eight triazolyl ligands and to fix the flexible polyether linkers of the final cage. The "click" reaction following classical reaction conditions with $\mathrm{CuSO}_{4}$ as catalyst and sodium ascorbate in $\mathrm{DMF}^{7 b}$ afforded

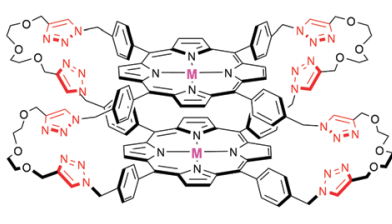

$$
\text { 1: } M=Z n(I I)
$$

2: $M=2 \mathrm{H}$

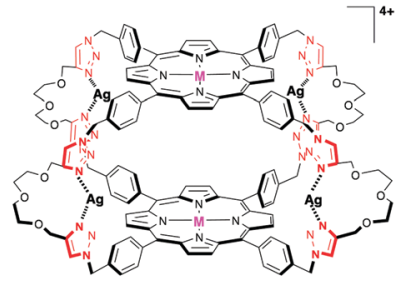

$\left[\mathrm{Ag}_{4}(1)\right]^{4+}: \mathrm{M}=\mathrm{Zn}(\mathrm{II})$ $\left[\mathrm{Ag}_{4}(2)\right]^{4+}: \mathrm{M}=2 \mathrm{H}$
Fig. 1 Graphical representations of cages 1, 2 and the silver(I)-complexed cages $\left[\mathrm{Ag}_{4}(1)\right]^{4+}$ and $\left[\mathrm{Ag}_{4}(2)\right]^{4+}$. 

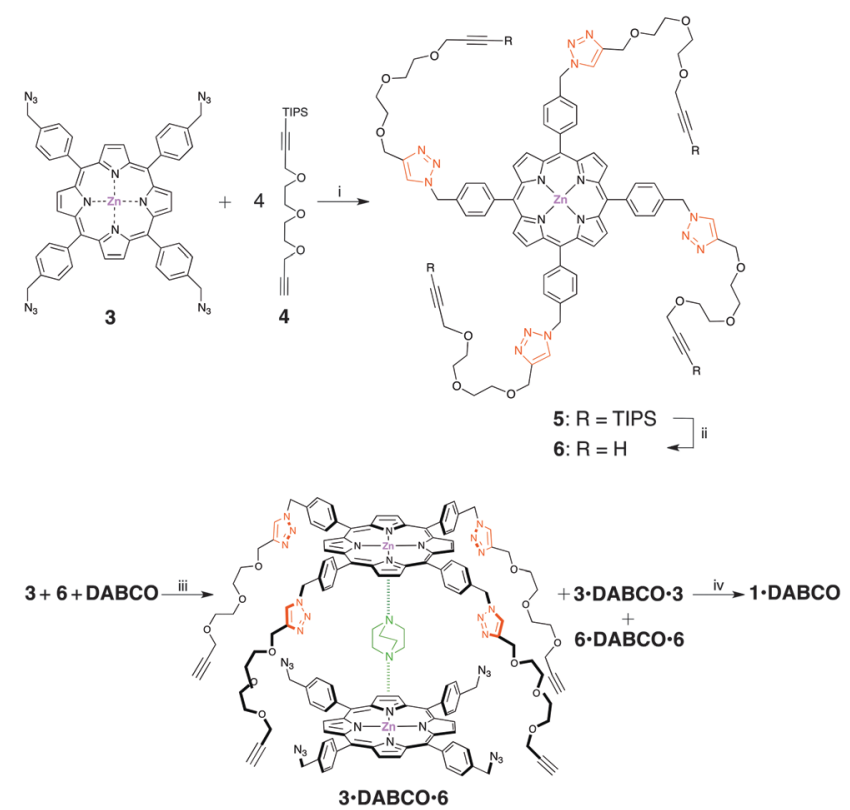

Fig. 2 DABCO-templated CuAAC synthesis of the cage 1.DABCO. (i) $\mathrm{CuSO}_{4}$, sodium ascorbate, DMF, $89 \%$; (ii) TBAF, THF, $63 \%$; (iii) $\mathrm{CH}_{2} \mathrm{Cl}_{2}$; (iv) [Cu(tren)'] $\mathrm{Br}$, $\mathrm{Na}_{2} \mathrm{CO}_{3}, \mathrm{CH}_{2} \mathrm{Cl}_{2}$.

compound 5 in $89 \%$ yield. Deprotection of the TIPS-protected alkyne using TBAF in THF led to the second precursor of the cage, porphyrin 6 , in $63 \%$ yield.

To limit the formation of oligomers, a DABCO-templated CuAAC cyclisation reaction was selected to synthesize 1 from the porphyrinic precursors 3 and 6 (Fig. 2). Coordination of one equiv. of DABCO to an equimolar solution of 3 and 6 at $c=$ $1.0 \mathrm{mM}$ in $\mathrm{CH}_{2} \mathrm{Cl}_{2}$ led to a dynamic equilibrium mixture of three complexes, the DABCO-templated homo dimers 3.DABCO-3 and 6.DABCO-6, and the hetero dimer 3.DABCO-6. The cyclisation reaction performed on this reaction mixture at room temperature, using $\left[\mathrm{Cu}\left(\right.\right.$ tren $\left.\left.^{\prime}\right)\right] \mathrm{Br}^{11}$ as catalyst and $\mathrm{Na}_{2} \mathrm{CO}_{3}$ as a base was completed after 5 days. After purification by consecutive alumina and silica column chromatographies, which partially removed the DABCO, both 1.DABCO and $\mathbf{1}$ were obtained. The yield of the cyclisation reaction, calculated from the total amount of cage 1 obtained after quantitative removal of the DABCO with an excess of $\mathrm{MeOH}$ in $\mathrm{CH}_{2} \mathrm{Cl}_{2}$, was $25 \%$. Cages 1.DABCO and $\mathbf{1}$ were fully characterized by $1 \mathrm{D}$ and $2 \mathrm{D}-\mathrm{NMR}$ spectroscopy and high-resolution ESI mass spectrometry (HR ESI-MS). Unfortunately, the X-ray crystal structure obtained for 1-DABCO was not of sufficient quality but attested to the formation of the cage with the DABCO coordinated inside the cavity (Fig. SI16, ESI $\dagger$ ). However, single crystals of cage 1 suitable for X-ray diffraction analysis were obtained, by slow diffusion of $\mathrm{MeOH}$ into a solution of 1 in DMSO. $\$$ In the solid state, the cage adopts a flattened conformation with a distance of $3.81 \AA$ between the porphyrin mean planes (Fig. 3 and ESI $\dagger$ ). The zinc(II) porphyrins are in a slipped cofacial arrangement with a horizontal offset of $3.77 \AA$ and a vertical one of $4.13 \AA$ leading to an intramolecular $\mathrm{Zn} \cdots \mathrm{Zn}$ distance of $7.09 \AA$. The close distance between the porphyrins is consistent with $\pi-\pi$ interactions between the macrocycles

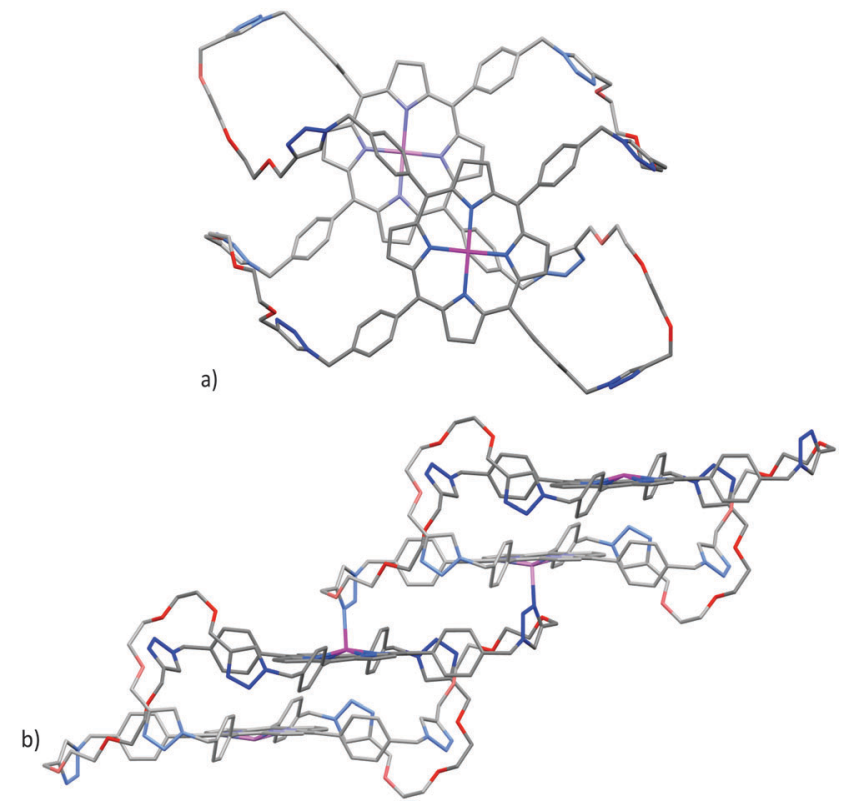

Fig. 3 Crystallographic structure of cage 1: (a) top view and (b) side view of the 1D coordination network. Colour code for the atoms: $\mathrm{N}$ blue, $\mathrm{Zn}$ purple, $\mathrm{O}$ red, $\mathrm{C}$ grey. $\mathrm{H}$ atoms and solvent molecules are omitted for clarity.

as shown from the overlapping of two pyrrole rings of each porphyrin. In the solid state, the two zinc metal centres are pentacoordinated and their axial positions are occupied by the triazoles of two neighbouring cages leading to a staircase like 1D coordination network (Fig. $3 b$ ).

Demetalation of the zinc(II) porphyrins of cage 1 using TFA in $\mathrm{CH}_{2} \mathrm{Cl}_{2}$ afforded the metal-free cage 2 in quantitative yield. In order to gain control on the cavity size by metal coordination to the peripheral triazolyl ligands, $\mathrm{Ag}(\mathrm{I})$ was selected for its versatile coordination sphere and its ability to form stable silver coordination cages with 3-pyridy $\mathrm{l}^{12}$ or bipyridyl appended porphyrins. ${ }^{13} \mathrm{Ag}(\mathrm{I})$ complexation was performed by addition of four equiv. of $\mathrm{AgSbF}_{6}$ in $\mathrm{CHCl}_{3} /$ $\mathrm{MeOH}(9: 1)$ solution to a solution of one equiv. of $\mathbf{1}$ dissolved in the same solvent mixture. A red solid precipitated immediately and could be dissolved in DMF- $\mathrm{d}_{7}$. The ${ }^{1} \mathrm{H}$ NMR spectrum (Fig. 4B) and DOSY experiment (Fig. SI45, ESI $\dagger$ ) attested to the formation of a single compound assigned to the desired $\left[\mathbf{A g}_{4}(\mathbf{1})\right]\left(\mathbf{S b F}_{6}\right)_{4}$ complex after full characterization including COSY and NOESY. This new species was further characterized by HR ESI-MS and the expected isotopic profile was obtained for $\left[\mathbf{A g}_{4}(\mathbf{1})\right]^{4+}$ detected as the major ionic species at $m / z=737.3615$ (Fig. SI46, ESI $\dagger$ ). Two other cations, $\left[\mathrm{Ag}_{3}(\mathbf{1})\right]^{3+}$ and $\left[\mathrm{Ag}_{2}(\mathbf{1})\right]^{2+}$, resulting from partial loss of silver during the analysis, were also detected. Similarly, the quantitative formation of $\left[\mathbf{A g}_{4}(2)\right](\mathbf{O T f})_{4}$ from the self-assembly of 2 with four equiv. of AgOTf was inferred from the ${ }^{1} \mathrm{H}$ NMR experiments (COSY, NOESY, DOSY) and HR ESI-MS characterization of the complex $\left[\mathrm{Ag}_{4}(2)\right]^{4+}$ (see ESI $\dagger$ ).

The ${ }^{1} \mathrm{H}$ NMR chemical shifts changes observed upon Ag(I) coordination gave us some information on the conformational changes induced by this metal ion. The porphyrins in cages 1 and 2 can be in close proximity or further apart (up to $17 \AA$ according to CPK-models) thanks to their long and flexible alkyl 

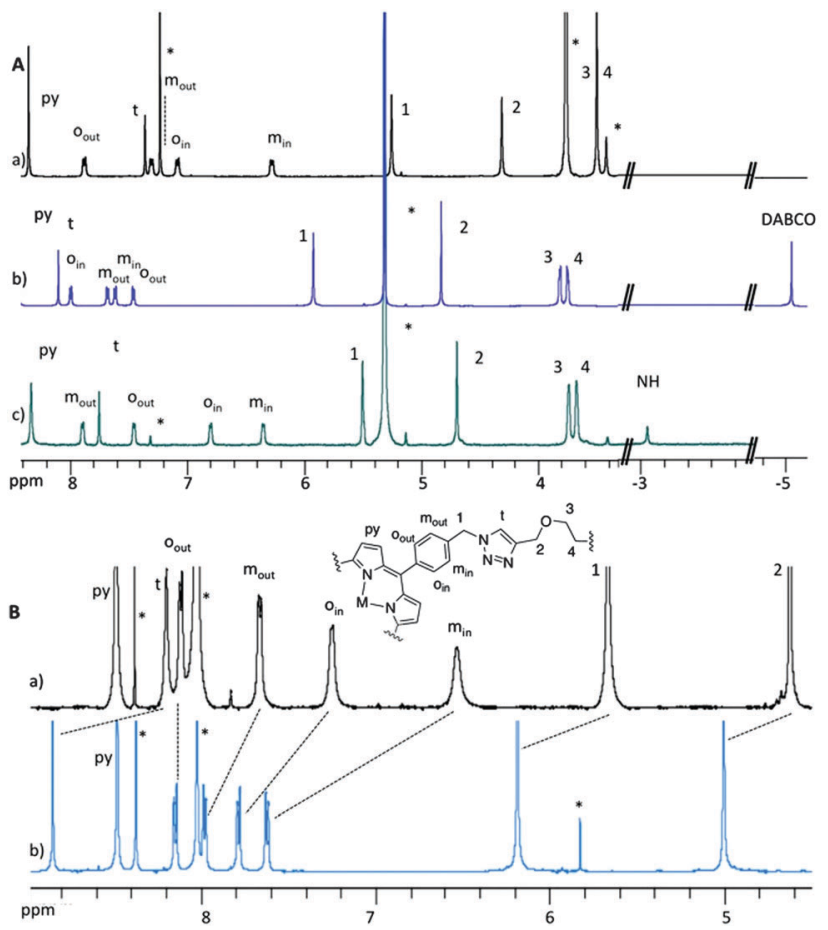

Fig. 4 (A) Partial ${ }^{1} \mathrm{H}$ NMR (298 K) of (a) 1 in $\mathrm{CDCl}_{3} / \mathrm{CD}_{3} \mathrm{OD} 10 \%(400 \mathrm{MHz})$; (b) 1.DABCO in $\mathrm{CD}_{2} \mathrm{Cl}_{2}(500 \mathrm{MHz})$; (c) 2 in $\mathrm{CD}_{2} \mathrm{Cl}_{2}(500 \mathrm{MHz})$; (B) partial ${ }^{1} \mathrm{H}$ NMR spectra $\left(500 \mathrm{MHz}, \mathrm{DMF}-\mathrm{d}_{7}\right)$ of (a) cage $\mathbf{1}$ and (b) $\left[\mathrm{Ag}_{\mathbf{4}}(\mathbf{1})\right]\left(\mathrm{SbF}_{6}\right)_{4}$; *: residual solvents.

ether connectors and several cage conformers could exist in solution. The formation of four peripheral $\mathrm{Ag}(\mathrm{I}) \mathrm{bis}($ triazole) complexes is expected to lock cages $\mathbf{1}$ and $\mathbf{2}$ in a well-defined conformation and to fix the relative spatial disposition of the porphyrins. The ${ }^{1} \mathrm{H}$ NMR spectra showed that cages $\mathbf{1}$ and $\mathbf{2}$ are of high symmetry in solution, as attested for example by the singlet observed for the 16 pyrrolic protons py or the sole signal observed for the benzylic protons 1 (Fig. $4 \mathrm{~A}(\mathrm{a})$ and $\mathrm{B}(\mathrm{a})$ ). The set of well-defined signals obtained indicates that the possible conformers of cage $\mathbf{1}$ or $\mathbf{2}$ would be in fast exchange at room temperature on the NMR chemical shift timescale. The variable temperature ${ }^{1} \mathrm{H}$ NMR experiment done in DMF failed to resolved different conformers (Fig. SI28, ESI $\dagger$ ). The ortho and meta protons of the meso porphyrin benzyl groups directed inside or outside the cavity experience a different chemical environment and gave two sets of doublets, $o_{\text {in }}, o_{\text {out }}$ and $\mathrm{m}_{\mathrm{in}}, \mathrm{m}_{\text {out }}$. Coordination of the triazole to zinc(II) porphyrin could be excluded in cage 1 from the close chemical shifts in DMF- $\mathrm{d}_{7}$ of the triazole protons in cage 1 and in zinc-free cage 2 at 8.20 and $8.32 \mathrm{ppm}$, respectively. The unusual chemical shifts of protons $m_{\text {in }}$ at $6.53 \mathrm{ppm}$ and $\mathrm{o}_{\text {in }}$ at $7.26 \mathrm{ppm}$ in cage $\mathbf{1}$ corresponding to an upfield shift of -1.12 and $-0.90 \mathrm{ppm}$ compared to the chemical shifts of the phenyl protons $\mathrm{m}$ and $\mathrm{o}$ in a zinc(II) mesotetratolylporphyrin (ZnTTP) indicate that these inner protons strongly experienced the ring currents of the proximate porphyrin and aromatic cycles (Fig. SI25, ESI $\dagger$ ). These phenomena, also observed on the ${ }^{1} \mathrm{H}$ NMR of 2 , suggest that cages $\mathbf{1}$ and $\mathbf{2}$ adopt in solution, as in the solid state for $\mathbf{1}$, an average flattened and slipped conformation favoured by $\pi-\pi$ interactions, as reported for other flexible covalently-linked porphyrin dimers. ${ }^{14}$

Upon formation of the silver-complexed cage $\left[\mathbf{A g}_{4}(\mathbf{1})\right]\left(\mathbf{S b F}_{\mathbf{6}}\right)_{\mathbf{4}}$, the chemical shifts were modified but no signal splitting was observed in accordance with the formation of a single complex of high symmetry (Fig. 4B). As expected, a downfield shift of $0.62 \mathrm{ppm}$ was observed for the eight triazole protons upon their coordination to $\mathrm{Ag}(\mathrm{I})$. Moreover, a high downfield shift was noticed for the aromatic protons $\mathrm{m}_{\mathrm{in}}$ and $\mathrm{o}_{\mathrm{in}}$, of 0.99 and $0.49 \mathrm{ppm}$, respectively, compared to a modest shift of $0.30 \mathrm{ppm}$ and $0.03 \mathrm{ppm}$ for protons $\mathrm{m}_{\text {out }}$ and $\mathrm{o}_{\text {out }}$. Protons 1 and 2 were also downfield shifted by 0.49 and $0.36 \mathrm{ppm}$, respectively. The same trend was observed on the ${ }^{1} \mathrm{H}$ NMR spectrum upon formation of the silver-complexed cage $\left[\mathbf{A g}_{4}(2)\right](\mathbf{O T f})_{4}$ (Fig. SI50, ESI $\dagger$ ). These observations indicate that coordination of four $\mathrm{Ag}(\mathrm{I})$ forces the cages $\left[\mathbf{A g}_{4}(\mathbf{1})\right]^{4+}$ and $\left[\mathbf{A g}_{4}(2)\right]^{4+}$ to adopt a new conformation which moves away the porphyrins whereas in cages 1 and 2, a compact conformation stabilized by $\pi-\pi$ interactions between the porphyrins and aromatic units is favoured. The DOSY NMR experiments in DMF- $\mathrm{d}_{7}$ corroborated these observations. The diffusion coefficients measured for $\left[\mathbf{A g}_{\mathbf{4}}(\mathbf{1})\right]\left(\mathbf{S b F}_{\mathbf{6}}\right)_{4}$ and for $\left[\mathrm{Ag}_{4}(2)\right](\mathbf{O T f})_{4}, 172 \mu \mathrm{m}^{2} \mathrm{~s}^{-1}$ and $180 \mu \mathrm{m}^{2} \mathrm{~s}^{-1}$ respectively, are lower than the ones obtained for cages 1 and 2, $186 \mu \mathrm{m}^{2} \mathrm{~s}^{-1}$ and $209 \mu \mathrm{m}^{2} \mathrm{~s}^{-1}$, respectively, in accordance with an overall larger volume for the silver-complexed cages. The UV-visible spectra recorded upon addition of incremental amounts of $\mathrm{Ag}$ (OTf) to a solution of $\mathbf{1}$ in $\mathrm{CH}_{2} \mathrm{Cl}_{2} / \mathrm{MeOH}(85: 15)$ gave also evidence of the conformational changes occurring upon silver(I) coordination (Fig. SI48, ESI $\dagger$ ). A large and non-Gaussian shaped Soret band was observed for the zinc(II) porphyrins in cage 1 with a half-band width of $18 \mathrm{~nm}$ and a maximum at $423 \mathrm{~nm}$ as compared to the Soret band of the reference ZnTTP ( $\lambda_{\max }: 425 \mathrm{~nm}$, half-band width: $11 \mathrm{~nm}$ ) (Fig. SI49, ESI $\dagger$ ). This band shape is consistent with electronic interactions between two porphyrins in close proximity. ${ }^{15}$ Upon addition of $\mathrm{Ag}(\mathrm{OTf})$, the Soret band became thinner, more intense and blue shifted by $5 \mathrm{~nm}$, as compared to ZnTTP. This hypsochromic shift is consistent, according to Kasha's exciton coupling theory, with a face-to-face disposition of the $\mathrm{Zn}(\mathrm{II})$ porphyrins in the final $\left[\mathbf{A g}_{4}(\mathbf{1})\right]^{\mathbf{4}}$ complex.

Coordination of $\mathrm{Ag}(\mathrm{I})$ is a reversible process. Decoordination of the four $\mathrm{Ag}(\mathrm{I})$ ions was achieved by addition of 10 equiv. of LiCl to a solution of $\left[\mathbf{A g}_{4}(\mathbf{1})\right]\left(\mathbf{S b F}_{6}\right)_{4}$ in DMF and ${ }^{1} \mathrm{H}$ NMR showed that the initial spectrum of cage $\mathbf{1}$ was restored (Fig. SI47, ESI $\dagger$ ).

The binding of DABCO inside cage $\mathbf{1}$ is also a reversible process. Addition of a solution of 1 equiv. of DABCO to a suspension of 1 in $\mathrm{CH}_{2} \mathrm{Cl}_{2}$ afforded 1.DABCO quantitatively, as shown by ${ }^{1} \mathrm{H}$ NMR, demonstrating the capability of the cage to modify its conformation to bind the ditopic ligand on the zinc porphyrins (see ESI $\dagger$ ). In cage 1-DABCO, the two porphyrins are in a face-to-face disposition with an interplanar distance of $7 \AA$, fixed by the DABCO ligand. As observed upon silver coordination, this cofacial arrangement resulted in a hypsochromic shift of the Soret band of 1.DABCO compared to the ZnTTP (Fig. SI17 and SI18, ESI†). Insertion of DABCO 
also increased the cage volume in agreement with the solid state structure and the lower diffusion coefficient measured by DOSY NMR for cage 1.DABCO, $428 \mu \mathrm{m}^{2} \mathrm{~s}^{-1}$, as compared to the one of cage $2,477 \mu \mathrm{m}^{2} \mathrm{~s}^{-1}$, both determined in $\mathrm{CD}_{2} \mathrm{Cl}_{2} \cdot{ }^{16}$

In conclusion, a DABCO-templated CuAAC reaction afforded $\mathbf{1}$, a large and flexible covalent cage incorporating eight triazoles and two Zn(II) porphyrins as active components. The metal-free cage 2 was obtained quantitatively after demetalation of the zinc(II) porphyrins. The reversible coordination of DABCO inside the cavity of $\mathbf{1}$ and the reversible binding of $\mathrm{Ag}$ (I) ions on the peripheral triazoles of cages 1 and 2 illustrated the orthogonal functions of the binding sites and the induced-fit ability of the structure. Whereas zinc metalated cage $\mathbf{1}$ and metal-free cage $\mathbf{2}$ adopt a compact conformation in solution stabilized by $\pi-\pi$ interactions, binding of four $\mathrm{Ag}(\mathrm{I})$ rigidifies the cage structure and locks the porphyrins in a cofacial disposition. $\operatorname{Ag}(\mathrm{I})$ acts as a chemical stimulus that fixes the cavity size and the porphyrins arrangement in cages 1 and 2. Such behaviour offers interesting perspectives for an allosteric control of the $3 \mathrm{D}$ porphyrinic cages reactivity.

The LaBex-CSC and the International Center for Frontier Research in Chemistry, icFRC (www.icfrc.fr) are gratefully acknowledged for financial support and for a $\mathrm{PhD}$ fellowship (LK). We also thank the ANR Agency for the financial support of the project ANR 14-CE06-0010 "Switchables cages". We are grateful to Dr Lydia Brelot (Crystallographic Service, Faculté de Chimie de l'Université de Strasbourg) for the structure determination of $\mathbf{1}$ and to Dr Eduardo C. Escudero-Adan (X-ray diffraction, ICIQ, Tarragona) for the one of 1-DABCO.

\section{Notes and references}

\$ X-ray crystallographic data. $\mathrm{C}_{70} \mathrm{H}_{68} \mathrm{~N}_{16} \mathrm{O}_{8} \mathrm{Zn}, M_{\mathrm{r}}=1326.77$, triclinic, space group $P \overline{1}, a=14.4171(10) \AA, b=16.6908(12) \AA, c=17.8550(13) \AA$, $\alpha=63.510(2)^{\circ}, \beta=76.3030(10)^{\circ}, \gamma=74.9150(10)^{\circ}, V=3676.5(5) \AA^{3}, Z=2$, $\rho_{\text {calc }}=1.199 \mathrm{~g} \mathrm{~cm}^{-3}, m=0.396 \mathrm{~mm}^{-1}, T=173 \mathrm{~K}$, radiation MoK $\alpha$ $(\lambda=0.71073 \AA), \theta_{\max }=28.115$, no. of meas. reflns: 83562 , no. of indep. reflns: $17779, R_{\mathrm{int}}=0.0350, R_{1}=0.0539, \mathrm{w} R_{2}=0.1678$. CCDC 1403732 .

1 P. Tompa, Chem. Rev., 2014, 114, 6715.

2 (a) J. Rebek, T. Costello, L. Marshall, R. Wattley, R. C. Gadwood and K. Onan, J. Am. Chem. Soc., 1985, 107, 7481; (b) T. Nabeshima, T. Inaba, N. Furukawa, T. Hosoya and Y. Yano, Inorg. Chem., 1993, 32, 1407; (c) S. Shinkai, M. Ikeda, A. Sugasaki and M. Takeuchi, Acc. Chem. Res., 2001, 34, 494; (d) L. Kovbasyuk and R. Krämer, Chem. Rev., 2004, 104, 3161; (e) R. S. Stoll and S. Hecht, Angew. Chem., Int. $E d ., 2010,49,5054$; $(f)$ M. J. Wiester, P. A. Ulmann and C. A. Mirkin, Angew. Chem., Int. Ed., 2011, 50, 114; $(g)$ C. Kremer and A. Lützen, Chem. - Eur. J., 2013, 19, 6162.

3 (a) S. Hiraoka, K. Harano, M. Shiro and M. Shionoya, Angew. Chem., Int. Ed., 2005, 44, 2727; (b) D. Ajami and J. Rebek, J. Am. Chem. Soc., 2006, 128, 15038; (c) D. Ajami and J. Rebek, J. Am. Chem. Soc., 2006, 128, 5314; (d) T. Gottschalk, B. Jaun and F. Diederich, Angew. Chem., Int. Ed., 2007, 46, 260; (e) K. Suzuki, M. Kawano and M. Fujita,
Angew. Chem., Int. Ed., 2007, 46, 2819; $(f)$ J.-R. Li and H.-C. Zhou, Nat. Chem., 2010, 2, 893; $(g)$ J. Hornung, D. Fankhauser, L. D. Shirtcliff, A. Praetorius, W. B. Schweizer and F. Diederich, Chem. - Eur. J., 2011, 17, 12362; (h) Y.-R. Zheng, W.-J. Lan, M. Wang, T. R. Cook and P. J. Stang, J. Am. Chem. Soc., 2011, 133, 17045; (i) Q.-F. Sun, S. Sato and M. Fujita, Nat. Chem., 2012, 4, 330; (j) A. Sørensen, A. M. Castilla, T. K. Ronson, M. Pittelkow and J. R. Nitschke, Angew. Chem., Int. Ed., 2013, 52, 11273; (k) X.-P. Zhou, Y. Wu and D. Li, J. Am. Chem. Soc., 2013, 135, 16062; ( $l$ ) J. MendezArroyo, J. Barroso-Flores, A. M. Lifschitz, A. A. Sarjeant, C. L. Stern and C. A. Mirkin, J. Am. Chem. Soc., 2014, 136, 10340.

4 (a) A. Mulder, A. Juković, F. W. B. van Leeuwen, H. Kooijman, A. L. Spek, J. Huskens and D. N. Reinhoudt, Chem. - Eur. J., 2004, 10, 1114; (b) M. Liu, X. Yan, M. Hu, X. Chen, M. Zhang, B. Zheng, X. Hu, S. Shao and F. Huang, Org. Lett., 2010, 12, 2558; (c) E. Busseron, J. Lux, M. Degardin and J. Rebek, Chem. Commun., 2013, 49, 4842; (d) M. Han, R. Michel, B. He, Y.-S. Chen, D. Stalke, M. John and G. H. Clever, Angew. Chem., Int. Ed., 2013, 52, 1319.

5 (a) D. M. Vriezema, M. C. Aragones, J. A. A. W. Elemans, J. J. L. M. Cornelissen, A. E. Rowan and R. J. M. Nolte, Chem. Rev., 2005, 105, 1445; (b) E. Iengo, F. Scandola and E. Alessio, Struct. Bonding, 2006, 121, 105; (c) T. S. Koblenz, J. Wassenaar and J. N. H. Reek, Chem. Soc. Rev., 2008, 37, 247; (d) M. Yoshizawa, J. K. Klosterman and M. Fujita, Angew. Chem., Int. Ed., 2009, 48, 3418; (e) T. R. Cook, Y.-R. Zheng and P. J. Stang, Chem. Rev., 2013, 113, 734; $(f)$ S. K. Samanta and M. Schmittel, Org. Biomol. Chem., 2013, 11, 3108; $(g)$ H. Ding, X. Meng, X. Cui, Y. Yang, T. Zhou, C. Wang, M. Zeller and C. Wang, Chem. Commun., 2014, 50, 11162; (h) S. Durot, J. Taesch and V. Heitz, Chem. Rev., 2014, 114, 8542; (i) B. Zhu, H. Chen, W. Lin, Y. Ye, J. Wu and S. Li, J. Am. Chem. Soc., 2014, 136, 15126; $(j)$ D. M. Wood, W. Meng, T. K. Ronson, A. R. Stefankiewicz, J. K. M. Sanders and J. R. Nitschke, Angew. Chem., Int. Ed., 2015, 54, 3988.

6 C. G. Oliveri, N. C. Gianneschi, S. T. Nguyen, C. A. Mirkin, C. L. Stern, Z. Wawrzak and M. Pink, J. Am. Chem. Soc., 2006, 128, 16286.

7 (a) J. E. A. Webb, F. Maharaj, I. M. Blake and M. J. Crossley, Synlett, 2008, 2147; (b) L. C. Gilday, N. G. White and P. D. Beer, Dalton Trans., 2012, 41, 7092; (c) J. H. Zhang, Y. J. Li, W. L. Yang, S. W. Lai, C. J. Zhou, H. B. Liu, C. M. Che and Y. L. Li, Chem. Commun., 2012, 48, 3602; (d) J. Zhang, X. Zheng, R. Jiang, Y. Yu, Y. Li, H. Liu, Q. Li, Z. Shuai and Y. Li, RSC Adv., 2014, 4, 27389.

8 J. Taesch, V. Heitz, F. Topic and K. Rissanen, Chem. Commun., 2012, 48, 5118.

9 L. Le Pleux, Y. Pellegrin, E. Blart, F. Odobel and A. Harriman, J. Phys. Chem. A, 2011, 115, 5069.

10 Z.-J. Yao, H.-P. Wu and Y.-L. Wu, J. Med. Chem., 2000, 43, 2484.

11 N. Candelon, D. Lastécouères, A. K. Diallo, J. Ruiz Aranzaes, D. Astruc and J.-M. Vincent, Chem. Commun., 2008, 741.

12 S. Durot, L. Flamigni, J. Taesch, T. T. Dang, V. Heitz and B. Ventura, Chem. - Eur. J., 2014, 20, 9979.

13 T. Nakamura, H. Ube and M. Shionoya, Angew. Chem., Int. Ed., 2013, 52, 12096.

14 (a) P. Leighton, J. A. Cowan, R. J. Abraham and J. K. M. Sanders, J. Org. Chem., 1988, 53, 733; (b) R. Karaman, A. Blasko, O. Almarsson, R. Arasasingham and T. C. Bruice, J. Am. Chem. Soc., 1992, 114, 4889.

15 (a) M. Kasha, H. R. Rawls and M. Ashraf El-Bayoumi, Pure Appl. Chem., 1965, 11, 371; (b) A. Satake and Y. Kobuke, Org. Biomol. Chem., 2007, $5,1679$.

16 The diffusion coefficients depend on the solvent viscosity according to the Stokes-Einstein equation ${ }^{17}$ and different values were obtained for cage 2 in $\mathrm{CD}_{2} \mathrm{Cl}_{2}$ or DMF- $\mathrm{d}_{7}$.

17 Y. Cohen, L. Avram and L. Frish, Angew. Chem., Int. Ed., 2005, 44, 520 . 